\title{
A POSITIVAÇÃO DOS DIREITOS DAS PESSOAS COM DEFICIÊNCIA NA PERSPECTIVA CONSTITUCIONAL E NORMATIVA NO CONTEXTO DA OBRIGATORIEDADE DE RESERVA DE VAGAS DE TRABALHO NA INICIATIVA PRIVADA E A ALTERNATIVA DE INCENTIVOS PARA CONTRATAÇÃO
}

\section{THE POSITION OF THE RIGHTS OF PERSONS WITH DISABILITIES IN THE CONSTITUTIONAL AND REGULATORY PERSPECTIVE IN THE CONTEXT OF THE REQUIREMENT FOR THE RESERVATION OF WORKING STAYS IN THE PRIVATE INITIATIVE AND THE ALTERNATIVE OF CONTRACTING INCENTIVES}

\author{
Roberto Carlos Ferreira Soares ${ }^{1}$ \\ Maria de Fátima Rodrigues de Oliveira ${ }^{2}$
}

Data de recebimento: $22 / 04 / 2018$

Data de Aprovação: 28/08/2018

\section{RESUMO}

O presente trabalho aponta as referências gravadas no texto constitucional que albergaram os direitos e garantias das pessoas com deficiência apresentando as principais legislações que possibilitaram a criação de uma rede protetiva, principalmente com destaque para a legislação que obrigou a inicia-

${ }^{1}$ Mestre em Sistema Constitucional de Garantias de Direitos pela Instituição Toledo de Ensino (ITE-Bauru/SP), pós-graduado em Administração de Recursos Humanos (Fundação Armando Alvares Penteado - FAAP), pós-graduado em Direito e Processo do Trabalho (Anhanguera/Uniderp), pós-graduado em Direito e Processo do Trabalho pelas Faculdades Metropolitanas Unidas (FMU). Psicólogo e Advogado. 
tiva privada reservar vagas de trabalho em seus quadros funcionais demonstrando uma forma impositiva de garantir o acesso ao trabalho cumprindo uma função importante do Direito de contrafacticidade ao mesmo tempo que pondera a necessidade de buscar alternativas que preencham os espaços que a referida lei não preencheu, possibilitando além da sanção negativa do Estado investido pelas autuações passando a incentivar com premiações positivas e formas de contribuição casos de incapacidade de atendimento da obrigação legal de reservar vagas.

\section{PALAVRAS-CHAVE}

Constituição; Pessoa com Deficiência; Reserva de Vagas; Trabalho; Incentivos.

\section{ABSTRACT}

The present study points out the references recorded in the constitutional text that housed the rights and guarantees of people with disabilities presenting the main legislation that made possible the creation of a protective network, especially with the legislation that forced the private initiative to reserve work places in its functional frameworks demonstrating a tax form of guaranteeing access to the work fulfilling an important function of the Right of counterfacticity while pondering the need to search for alternatives that fill the spaces that the law did not fill, allowing in addition to the negative sanction of the State invested by the notifications beginning to encourage with positive awards and forms of contribution cases of inability to meet the legal obligation to reserve vacancies.

\section{KEYWORDS}

Constitution; Person with Disability; Reservation of Vacancies; Job; Incentives. 


\section{INTRODUÇÃO}

A sociedade contemporânea atravessa um momento importante configurado pela busca de soluções que possibilitem respostas para problemas que afetam a integridade do tecido social visto em sua totalidade que traduzem em demandas que reclamam pela concretização de direitos aferidos pelo texto constitucional e ao mesmo tempo os atendimentos aos anseios individuais de cada integrante que traz em sua bagagem as necessidades de reconhecimento e espaço para realização pessoal.

A Constituição Federal de 1988 tratou com muito cuidado a questão da pessoa com deficiência, principalmente albergando direitos e garantias específicas em diversos momentos dentro do texto constitucional, alcançando diversos patamares da sociedade, com destaque para o trabalho, mobilidade, educação, previdência e a saúde.

É importante ressaltar que os tratados internacionais foram também fundamentais para incrementar os direitos das pessoas com deficiência, como dentre outros, a Convenção Internacional sobre os Direitos das Pessoas com Deficiência, cujo empenho desses tratados não será mérito de abordagem desse trabalho.

$\mathrm{O}$ foco do constituinte foi a preocupação de integrar a pessoa com deficiência no seio da sociedade como membro atuante e participante na conformidade com o princípio da dignidade da pessoa humana.

Neste sentido é delineado os marcos constitucionais que serviram de referência para apresentação dos direitos e garantias das pessoas com deficiência.

Com a construção da rede normativa que regulou os direitos que foram assegurados na Constituição Federal, de tal sorte que possibilitou uma blindagem formada por legislações protetivas que possibilitaram inclusive a referência necessária para implantação de políticas públicas assertivas que preconizam ainda mudanças sociais que garantam a efetividade desses direitos postos pelo constituinte originário.

O momento seguinte é apresentação da obrigação normativa da reserva de vagas de trabalho a serem cumpridas pela iniciativa privada considerando que apesar da elasticidade da lei em albergar também os reabilitados, 
o foco neste trabalho são as pessoas com deficiência trazendo uma reflexão quanto as condições de imposição, bem como da atuação dos auditores do trabalho como coatores do cumprimento legal.

O passo final trata da possibilidade de buscar alternativas para cumprimento do objetivo de integração da pessoa com deficiência no mercado de trabalho apontando a a ponderação de implantação de incentivos por sanções positivas, bem como o incremento de contribuições para aquelas situações em que a obrigatoriedade não alcança o resultado de efetividade.

\section{OS MARCOS REFERENCIAIS PROPORCIONADOS PELA CONSTITUIÇÃO FEDERAL DE 1988}

A Constituição da República Federativa do Brasil, de 05 de outubro de 1988, trouxe diversos dispositivos que tratam da proteção da pessoa com deficiência. É bem verdade que o legislador originário conferiu tratamento privilegiado em relação aos demais grupos que não estão inseridos na categoria dos deficientes.

A Constituição de 1988 realmente foi determinante no tocante à consagração dos direitos das pessoas com deficiência, ainda mais esses direitos não são encontrados em um local específico da Constituição de 1988, mas são apresentados ao longo de todo o texto constitucional.

Essa ideia pode ser melhor entendida quando se observa o fundamento estabelecido no inciso III do artigo $1^{\circ}$ da Constituição de 1988 que consagra a dignidade da pessoa humana como um princípio fundamental do Estado Democrático de Direito que se aproxima com um dos objetivos estampados no artigo $3^{\circ}$, inciso IV: "promover o bem de todos, sem preconceitos de origem, raça, sexo, cor, idade e quaisquer outras formas de discriminação", consequentemente atrela a condição igualitária para as pessoas com deficiência.

Já o artigo $7^{\circ}$, inciso XXXI no texto constitucional expressa a proibição do empregador de estabelecer critérios para admissão e de salário às pessoas com deficiência.

Esse inciso talvez seja o ponto crucial para a inserção da pessoa com deficiência no mercado de trabalho, já que na condição de minoria, recebe os 
menores salários, inclusive sendo difícil a constatação da discrepância salarial nas organizações empresariais, pois executam em muitos casos, tarefas que são as mesmas que as dos outros empregados.

$\mathrm{O}$ artigo 37, inciso VIII trata da reserva de percentual dos cargos e empregos públicos para as pessoas com deficiência. A garantia de fruição foi regulação da Lei $\mathrm{n}^{\circ} 8.112 / 90$, que previu os requisitos básicos para investidura em cargos públicos (artigo $5^{\circ}$, incisos I a VI, e $\S 1^{\circ}$ ) e o direito das pessoas com deficiência de participarem dos certames, destinando-lhes percentual máximo de reserva de vagas $\left(\operatorname{artigo} 5^{\circ}, \S 2^{\circ}\right.$ ) de até $20 \%$ das vagas oferecidas no concurso.

Já, o artigo 37 do Decreto n $3.298 / 99$, que dispõe sobre a Política Nacional para a Integração da Pessoa Portadora de Deficiência assegura às pessoas com deficiência o direito de se inscreverem em concursos públicos nas mesmas condições de igualdade com os demais candidatos para o provimento de cargos cujas atribuições sejam compatíveis com suas deficiências reservando-lhes no mínimo 5\% das vagas do certame.

Portanto, enquanto o artigo $5^{\circ}, \S 2^{\circ}$ da Lei $n^{\circ} 8.112 / 90$ determina o percentual máximo de vagas que devem ser destinadas aos candidatos com deficiência, fixando-as em até $20 \%$, o artigo 37 do Decreto $n^{\circ} 3.298 / 99$ estabelece o percentual mínimo, fixando-a em $5 \%$.

Logo, na prática verifica-se que os editais de concursos públicos têm fixado o percentual mínimo de vagas reservadas para as pessoas com deficiência como forma positiva de acesso ao mercado de trabalho na esfera pública.

No tocante à Previdência Social, o artigo 201, § $1^{\circ}$ da Constituição Federal de 1988 abre exceção para adoção de critérios diferenciados para segurados com deficiência que foi regulada pela Lei Complementar $\mathrm{n}^{\circ} 142$, de 08 de maio de 2013, que trouxe redução da idade para a concessão de aposentadoria por idade para a pessoa com deficiência.

Na sequência do texto constitucional, o artigo 203 abre a seção da assistência social preconizando que o Estado, no inciso IV, deverá possibilitar a habilitação e reabilitação, bem como a promoção à integração à vida em sociedade e o inciso $\mathrm{V}$ estabelece a garantia de um salário mínimo de benefício mensal à pessoa com deficiência.

O artigo 227, § $1^{\circ}$, inciso II estabelece a obrigação do Estado em desen- 
volver programas de prevenção e atendimento especializado para as pessoas com deficiência, bem como forma de integração do adolescente com deficiência mediante atendimento especializado que possui conexão com o artigo 11, $\S \S 1^{\circ}$ e $2^{\circ}$ que tratam especificamente da criança e do adolescente com deficiência, no Estatuto da Criança e do Adolescente.

$\mathrm{O} \S 2^{\circ}$ do artigo 227 estabelece que a lei irá dispor sobre as normas de construção dos logradouros, edifícios de uso público e a fabricação de veículos de transporte coletivo, a fim de garantir acesso adequado às pessoas com deficiência.

A competência para a efetivação desses direitos foi determinada pelo constituinte originário, que no artigo 23 entendeu como sendo comum aos membros da Federação: a União, os Estados, o Distrito Federal e os Municípios a responsabilidade elencada no inciso II: "cuidar da saúde e assistência pública, da proteção e garantia das pessoas portadoras de deficiência".

De forma concorrente pelo artigo 24, inciso XIV, a União, os Estados e o Distrito Federal deverão garantir a proteção e integração social das pessoas com deficiência. Por força do $\S 1^{\circ}$ do referido artigo, enquanto a União estabelece normas gerais e os Estados e o Distrito Federal de forma suplementar pelo $\S 2^{\circ}$ e pelo entendimento do $\S 3^{\circ}$ enquanto não houver norma geral por parte da União regulando a matéria, os Estados e o Distrito Federal terão competência plena, até a União pronunciar sobre o tema por orientação do $\S 4^{\circ}$ que suspende a eficácia naquilo que colidir.

Para Luiz Alberto David Araújo e Vidal Serrano Nunes Júnior (2013, p. 54): “[...] os artigos 21, 22 e 24 produzem todos os seus efeitos de imediato, pois entendem que não necessitam de qualquer integração legislativa infraconstitucional."

Esse entendimento se refere a eficácia plena, conforme pensamento de José Afonso da Silva (1998, p. 101): “[...] aquelas que, desde a entrada em vigor da Constituição, produzem, ou tem possibilidade de produzir, todos os efeitos essenciais, relativamente aos interesses, comportamentos e situações que o legislador constituinte, direta e normativamente, quis regular."

Os Municípios não ficaram excluídos neste contexto, por força do artigo 30, os incisos. I e II especificam que podem legislar sobre assunto de inte- 
resse local e de forma suplementar.

O rol de direitos estabelecido pela Constituição de 1988 no tocante às pessoas com deficiência é elástico, de tal sorte determina em vários momentos o entendimento que a máquina estatal deve produzir políticas públicas para atender às premissas constitucionais.

Neste ínterim, a falta de eficácia dos direitos preconizados pela Constituição Federal de 1988, poderá revelar o distanciamento entre a norma e a realidade que acompanhou o constitucionalismo brasileiro pelas décadas anteriores (BARROSO, 2014, p. 276).

Para Glauco Roberto Marques Moreira (2008, p. 37): “as pessoas portadoras de deficiência classificam-se entre aquelas pessoas que reclamam da lei o tratamento discriminatório positivo que as protejam nas suas desigualdades (deficiência)". Para alcançar esse atendimento necessitam que as regras contidas e explícitas da Constituição de 1988 sejam distribuídas através de legislações que aumentem sua eficácia regulando matérias específicas, identificando as funções e natureza das ações que coordenadas e inter-relacionadas entre si formam um sistema de normas que fortalecem a blindagem de direitos.

O leque de proteção às pessoas com deficiência estabelecido pela Constituição de 1988 foi sem igual quando comparado às outras Constituições brasileiras, haja vista que somente a Constituição de 1967 trouxe, de forma explícita, alguma consideração quanto ao atendimento às pessoas com deficiência.

A construção desses dispositivos constitucionais possibilitou que houvesse crescente número de legislações infraconstitucionais que tratassem de diversas matérias que versassem sobre os direitos das pessoas com deficiência, fazendo com que houvesse um fortalecimento ou uma blindagem dos direitos e corroborando para aumentar a discussão quanto à efetividade dessas normas jurídicas.

\section{A BLINDAGEM DO ORDENAMENTO COMO PROTEÇÃO DOS DIREITOS DAS PESSOAS COM DEFICIÊNCIA}

A determinação expressa do artigo 93 com seus inciso e parágrafos 
da Lei $\mathrm{n}^{\circ} 8.213$, de 24 de julho de 1991 obrigou a contratação de pessoas com deficiência pelas empresas privadas, não foi um ato jurídico isolado do contexto social e histórico, mas o resultado de todo um processo que foi marcado pela evolução do pensamento que tratou dos direitos fundamentais do homem cujos marcos foram também evidenciados pelos documentos históricos e pelos ordenamentos que tratavam dos direitos humanos.

A legislação que trata dos direitos das pessoas com deficiência é fator fundamental para nortear as discussões que pairam sobre a inclusão no seio da sociedade contemporânea.

O significado da importância das legislações se deve ao fato do reconhecimento na necessidade da positivação como garantia estendida de atendimento e cumprimento das obrigações que são emanadas pelo texto legal, fazendo com que as divergências sejam minimizadas para a concentração de ações de atendimento às demandas específicas.

É bem verdade que o sentido da importância da norma jurídica é reconhecido pelo valor igualitário que se submete à comunidade envolvida e também possui como uma das principais características a contrafacticidade que tão bem foi exposta por Dimitri Dimoulis (2013, p. 100), que ensina que a validade da norma jurídica se mantém mesmo quando contrariada, portando traz o significado de que mesmo sendo contrária aos fatos reais no sentido de enfrentamento da realidade e suas tendências, a norma jurídica deve prevalecer, principalmente quando propõem mudar a realidade social ou pretende impedir a manifestação de determinada conduta considerada prejudicial ao desenvolvimento objetivado pela cultura.

A posição defendida pelo autor expressa o fundamento que objetiva mudar a realidade social, transformar o comportamento dos homens e das relações sociais, na medida em que representa um fator de transformação mediante valores alicerçados na esfera democrática buscando alcançar realidades condizentes com a dignidade da pessoa humana.

Questão essa interessante, principalmente quando enfrentada a obrigação da iniciativa privada em contratar pessoas com deficiência, sabendo da ocorrência de custos para implantação, adequação dos espaços laborais, ainda assim permanece sob a égide da penalidade na contraposição da 
responsabilidade social.

Essa singularidade de prevalência característica da norma jurídica também encontra outro sentido de não ser prejudicada quando desrespeitada, ou seja, mesmo não sendo cumpridas as determinações que são impostas pelo texto legal, a sua existência não é afetada, mas na maioria dos casos quando do não cumprimento impõe alguma sanção.

De modo semelhante, a norma também traduz uma condição conservadora que se manifesta pela vontade da manutenção da situação atual, no sentido de impedir mudanças sociais que tragam prejuízos à coletividade e para isso utiliza mecanismos inibitórios plasmados, principalmente, nas sanções.

Essa visão do Direito possibilita através do formato de alterar o contexto social adverso pela vontade da lei, mas sendo cogente, força e conduz a alteração da realidade mediante a coação que a norma jurídica estabelece.

O que efetivamente caracteriza uma norma jurídica nas palavras de Miguel Reale (2003, p. 95): “[...] é o fato de ser uma estrutura proposicional enunciativa de uma forma de organização ou de conduta, que deve ser seguida de maneira objetiva e obrigatória" e é considerado como uma estrutura proposicional porque o seu conteúdo pode ser enunciado mediante o apontamento de preposições ou enunciados que se apresentam de forma ordenada.

Isso significa que a norma jurídica enuncia um dever ser que, por sua vez, só tem sentido enquanto se ordena e se atualiza através de um sistema de disposições que traçam os âmbitos de ação e de competência que devem ser respeitados pelos membros da Federação.

Sobre tal aspecto, importante assinalar o pensamento de Eros Roberto Grau (2003, p. 64) que aponta que o legislador não pode estabelecer qualquer forma de direito. A própria sociedade gera um direito pressuposto que é determinado pelo modo de produção que envolve diretamente o sistema econômico e pela correlação das forças políticas. O direito pressuposto determina os principais conteúdos de cada sistema jurídico, ou seja, oferece as bases para a criação do direito posto, elaborado e aplicado pelo Estado. O direito posto é aquele que transparece pelo Estado, enquanto o direito pressuposto se manifesta no interior da sociedade retratada pela faceta histórico-cultural, de tal sorte que o legislador não está livre para criar as normas jurídicas, mas antes disso, está 
contaminado pela realidade da estrutura social.

A esse propósito, a elaboração de ordenamentos atrela, em muito, o momento histórico que a sociedade atravessa principalmente como afeta a vida das pessoas nas suas relações interpessoais de tal maneira que provoca reações algumas vezes motivadas pela vontade popular ou em outros casos são fomentadas por interesses de grupos que desejam a mudança de determinado comportamento social.

Ainda assim, essas reações não se distanciam de um antecedente ou do momento histórico que entrelaça ao fato denotador, o que aproxima com o pensamento de Michael J. Sandel (2012, p. 275) explicando que a história de vida de cada pessoa está em muito ligada a sua história dentro de sua comunidade, tanto de forma positiva que possibilite conduzir no mesmo sentido de aspiração do grupo social antecessor, como também opor aquilo que era querido pela linhagem original.

No tocante às normas jurídicas com relação as garantias e os direitos das pessoas com deficiência, ao abordar o tema acessibilidade e locomoção da pessoa com deficiência e seus direitos constitucionais, José Raimundo de Carvalho destaca (2012, p. 34):

[...] o grande problema em relação à inclusão das pessoas com deficiência reside não na falta de normas ou de competência para aplicação, mas na falta de efetividade de tais normas, aliada a uma certa resistência da comunidade e do próprio Poder Público em implementá-las, o que provoca um distanciamento da meta de tornar a inclusão da pessoa com deficiência um fato e não uma aspiração.

Com relação ao problema levantado, aponta a necessidade de que os membros da Federação desenvolvam, em conjunto, medidas coordenadas que possibilitem a eliminação das barreiras, principalmente aquelas que dificultam a acessibilidade das pessoas com deficiência (CARVALHO, 2012, p. 34).

A compreensão das obrigações que determinam a contratação de pessoas com deficiência nos quadros da iniciativa privada não é fator isolado da vontade do legislador ordinário. Antes disso, as diretrizes foram estabelecidas 
na Constituição da República Federativa do Brasil de 1988 no escopo do tratamento dado aos direitos das pessoas com deficiência.

\section{A OBRIGAÇÃO DA INICIATIVA PRIVADA DE RESERVAR VAGAS DE TRABALHO PARA PESSOAS COM DEFICIÊNCIA}

A legislação brasileira que trata da obrigação de contratar pessoas com deficiência na esfera da iniciativa privada ficou reservada no artigo 93 e os seus $\S \S 1^{\circ}$ e $2^{\circ}$ da Lei $n^{\circ} 8.213$, de 24 de julho de 1991, que recentemente sofreu alteração pela Lei $n^{0}$ 13.146, de 06 de julho de 2015, conhecida como Lei Brasileira de Inclusão da Pessoa com Deficiência ou Estatuto da Pessoa com Deficiência.

Ao analisar o contexto do artigo mencionado acima, encravado dentro do contexto da Lei $\mathrm{n}^{\circ} 8.213$, de 24 de julho de 1991, logo se percebe que a referida legislação trata sobre os assuntos referentes aos benefícios da Previdência Social, de tal sorte que ao avançar sobre as matérias ali dispostas, o legislador teve a preocupação inicialmente de elencar no texto legal os princípios e objetivos que norteiam o sistema da Previdência Social, a composição e atribuições do Conselho Nacional de Previdência Nacional Social, os regimes de Previdência Social - os beneficiários, as prestações e suas modalidades.

Neste ínterim foi inserida no artigo 93 a matéria que destoa do objetivo da lei, ou seja, a obrigação de contratação de pessoas com deficiência conforme percentual calculado sobre o quadro de pessoal a partir de 100 a 200 terá de contratar $2 \%$, de 201 a 500 o percentual de 3\%, de 5001 a 1000 o percentual de $4 \%$ e acima 1001 o correspondente a $5 \%$.

$\mathrm{O} \S 1^{\mathrm{o}}$ apontado na nova redação mostra uma melhoria que esclarece que a regra da dispensa (rescisão de contrato) de beneficiário considerado reabilitado pela Previdência Social, ou empregado com deficiência ao final de contrato por prazo determinado acima de 90 dias e a dispensa imotivada no contrato de trabalho por prazo indeterminado que somente poderá ser concretizada após a contratação de outro reabilitado ou pessoa com deficiência.

Aspecto importante determinado pela lei no $\S 2^{\circ}$ é a responsabilidade atribuída ao Ministério do Trabalho e do Emprego - MTE quanto à geração e à consolidação dos dados e estatísticas sobre a realidade laboral dos empregados 
com deficiência, tendo em vista a necessidade de aprimoramento das informações prestadas ao público em geral para contribuir, de forma direta e imediata, com dados atualizados que atendam aos pesquisadores, aos sindicatos, às entidades representativas dos empregados ou aos cidadãos interessados.

A efetividade da fiscalização quanto ao cumprimento da cota cabe aos auditores do trabalho do MTE regulamentada pela Instrução Normativa ${ }^{0}$ 98, de 15 de agosto de 2012, que disciplinou a fiscalização e cumprimento por parte dos empregadores com relação ao atendimento às normas destinadas à inclusão no trabalho das pessoas com deficiência e beneficiários reabilitados da Previdência Social.

Ainda com relação à demanda imposta ao MTE quanto à gestão dos dados, as informações prestadas são importantes para verificar, inclusive, a efetividade do cumprimento da obrigação, isto é, se os dados estatísticos validam o preceito da obrigação.

As informações que atualmente estão disponibilizadas no site do MTE são limitadas no sentido de fornecerem relatórios gerais principalmente que demonstram os resultados das fiscalizações que englobam diversos temas que compõem o objeto da fiscalização dos agentes do MTE e dentre esses, o preenchimento dos postos de trabalho reservados para as pessoas com deficiência.

A própria atuação da fiscalização do MTE quando audita empresa, normalmente o faz pela matriz da organização empresarial e verifica nesta as informações, no caso do atendimento do percentual de reserva de postos de trabalho para as pessoas com deficiência, logo, se a matriz concentra todo seu contingente de obrigação de empregados com deficiência em uma determinada localidade, resolve-se favoravelmente ao empregador, mas não representa garantia de acesso ao trabalho para outras pessoas com deficiência que vivem em centros menores que poderiam ter acesso ao trabalho através da contratação pelas filiais.

Ainda assim, o modelo brasileiro se posiciona pela obrigação de que as empresas privadas devem contratar conforme o preceito do artigo da lei, mas as determinações legais não conseguem acompanhar a dinâmica do mercado de trabalho, pois diversos segmentos não são lineares, como o da prestação de serviços de segurança privada que pela característica de trabalho agre- 
gam disponibilidade de serviços de vigilância armada.

O fato é que a contratação da pessoa com deficiência conduz à necessidade, muitas vezes, de adequar o ambiente de trabalho com móveis e equipamentos de trabalho na condição de operabilidade para o trabalhador com deficiência. Não é somente isso, ocorre que serão necessárias medidas para treinamento para o pessoal com deficiência para se integrar na rotina de produção, sensibilização com os demais empregados, o que denotará maior tempo para maturação profissional e aquisição de segurança operativa

Essas peculiaridades naturalmente serão computadas nas planilhas de orçamento do empresário, que repassará para o consumidor de bens e serviços esses custos decorrentes ao processo de produção, que deverão ser suportados pelos seus clientes.

Decorre que o mercado é extremamente competitivo, que obriga a constante reengenharia organizacional para adequação dos custos com os benefícios aferidos, obrigando a colocar tanto bens, como serviços com preços competitivos no mercado de consumo.

A fórmula empresarial brasileira sempre foi a maximização dos lucros com o menor custo, o que leva muitos empresários a cumprir o percentual que o artigo 93 da Lei $n^{\circ} 8.213$ determina pela obrigação e não por interesse social.

Desse desalinhamento decorrem das mais diferentes formas de fraudes trabalhistas que vão desde o registro de contrato na Carteira de Trabalho e Previdência Social mediante o consentimento da pessoa com deficiência com o empregador que remunera sem a efetiva prestação dos serviços, até a empregar pessoas com deficiência através da terceirização da mão de obra (SASSAKI, 2010, p. 88).

Neste desarranjo, alguns empresários optam por pagar as multas aplicadas pelos auditores do MTE por entenderem que os custos com a manutenção da contratação e com as adaptações no ambiente de trabalho representam uma desvantagem financeira que não é minimizada pelo retorno de seus investimentos.

Esse raciocínio demonstra a mentalidade que define o custo benefício traduzido pelo desconhecimento da responsabilidade social que os empregadores possuem ao assumirem o risco econômico mediante a exploração da 
mão de obra, muitas vezes pelo discurso da competitividade que o mercado globalizado imprime na tônica de redução de despesas para a composição de preços competitivos.

A tônica da responsabilidade social das empresas descentraliza a discussão da maximização do lucro e aponta para uma convergência de sustentabilidade de recursos, ideia apontada nos estudos para criação e desenvolvimento de empresas no contexto colombiano com responsabilidade social de Alberto Ibarra Mares e Alexander Castrillo Gaván (2013, p. 49) como: “[...] nueva dimensión empresarial preocupada por el concepto de sostenibilidad, en el que converjan a un mismo nivel los aspectos económicos, sociales y medioambientales, aun a costo del crecimiento de la empresa".

A tradução da ideia está na combinação dos fatores de produção, sociais e ambientais para que os ganhos sejam para todos e não somente para benefício econômico.

Esse estranho panorama é somado ainda pelo fato que a mão de obra com deficiência, na maioria dos casos, ainda necessita de treinamento específico, os quais denotam investimentos de equipamentos e a capacitação de instrutores para ministrarem treinamentos de operação e habilidade no trabalho.

Além da questão de adaptação das condições de trabalho, sabe-se que as empresas recrutam no mercado de trabalho profissionais capacitados com experiências desenvolvidas para que não tenham custos em treinamentos de capacitação, nos quais denotariam considerável tempo para que o profissional estivesse preparado para a execução de tarefas dentro de um parâmetro esperado de produção.

A capacitação e a preparação para o mercado de trabalho em condições de igualdade com os outros profissionais denotam uma necessidade de aprimoramento do profissional com deficiência, o que historicamente o distingue em função da discriminação dentre outras, pela condição de sua natureza.

Neste sentido, a falta de capacitação profissional pela baixa escolaridade fator que também dificulta, inclusive, a inserção pela obrigatoriedade de contratar devido à dificuldade de encontrar pessoas com deficiência que possam preencher requisitos mínimos para o perfil da vaga.

A legislação ao trazer a obrigatoriedade de contratar pessoas com de- 
ficiência, também pode resultar na criação de outros preconceitos, conforme pensamento de Ives Gandra Martins (1996, p. 71):

$\mathrm{O}$ argumento antidiscriminação cria uma discriminação às avessas. A criação de reserva de mercado ou de área de ação apenas para as pessoas consideradas excluídas resulta num processo inverso de discriminação, em vez de levar à eliminação de alguns preconceitos ainda não erradicados, como almejam os adeptos dessas teses.

O autor traduz o entendimento que a argumentação da antidiscriminação gera outra discriminação pelo fato do benefício proporcionado traduzir uma exceção à regra da competitividade.

O legislador infraconstitucional, no $\S 1^{\circ}$ do artigo 93 da Lei $n^{\circ} 8.213 / 91$, determina que a dispensa imotivada do trabalhador com deficiência somente ocorrerá após a contratação de outro trabalhador com deficiência. Essa condição imposta aumenta a dificuldade em dispensar o empregado com deficiência, o que não ocorre na contrapartida com o empregado sem deficiência que não possui essa proteção.

Essa condição peculiar criada trazida pela norma, sem dúvida procurou proteger e garantir que as vagas reservadas fossem preservadas desmotivando o empregador de dispensar a mão de obra com deficiência na mesma condição dos demais empregados.

A dispensa sem justa causa do empregado com deficiência gera custo com as verbas rescisórias e a contratação de outra pessoa com deficiência para preencher a vaga, obriga o empregador a contratar primeiro para dispensar depois.

A diferença de tratamento pode traduzir nos demais empregados uma discriminação no ambiente de trabalho pela proteção advinda do artigo da lei, que pode representar empecilho na integração da pessoa com deficiência no ambiente de trabalho.

O sentimento gerado dentro do ambiente de trabalho pode revelar discriminação contra os empregados com deficiência que gozam de garantia de emprego diferenciada de outros empregados. 
A falta de desenvolvimento de ações de sensibilização com os demais empregados com relação à integração da pessoa com deficiência no ambiente de trabalho pode resultar na geração de dificuldades de relacionamento, prejudicando ainda mais as pessoas com deficiência.

Para desenvolver medidas preventivas, a estratégia na gestão de clima empresarial necessariamente determina ações voltadas para a interação do empregado com deficiência com os demais empregados no local de trabalho deve envolver a planta empresarial com explicações de termos de fácil compreensão, principalmente com o envolvimento dos representantes sindicais, conforme diretrizes da OIT (2002, p. 21): "debería comunicarse a todos los trabajadores una información general acerca de las discapacidades en el lugar de trabajo [...]", inclusive divulgar as estratégias empresariais para as melhorias do ambiente de trabalho para que os empregados com deficiência possam desempenhar suas tarefas com eficiência.

Segundo Pastore (2000, p. 183): “a controvérsia, em torno de cotas tende a prosseguir. Os empregadores, em geral, se opõem ao sistema [...]" e aponta em seu raciocínio que os países onde há cotas, se observam que o sistema está perdendo força.

Não é por menos, as oscilações das condições econômicas globais que afetam as economias regionais obrigam os empresários a moldar o tempo todo o negócio, tendo que se adaptarem às flutuações e incertezas dos mercados, fazendo com isso o ajuste do quadro de pessoal.

O empregado com deficiência, neste contexto, também sofre os mesmos revezes daquele que não tem deficiência.

O avanço garantido pela obrigação do artigo da lei, não pode ficar atrelado somente ao cumprimento do percentual de contratação, mas deve avançar no sentido de promover ações e medidas que incentivem a contratação ao mesmo tempo em que disponibilize alternativas de aprimoramento profissional, dando às pessoas com deficiência condições de igualdade no mercado de trabalho sempre competitivo e volátil que obriga a todos a adaptação pelo desenvolvimento de competências.

O sentido dado pelo legislador infraconstitucional ao descrever a finalidade das políticas públicas de trabalho no artigo 35 do Estatuto da Pessoa 
com Deficiência é a promoção e garantias de condições de acesso e de permanência da pessoa com deficiência no campo de trabalho.

Logo, o modelo brasileiro não pode somente permanecer na obrigação de determinar que o setor privado contrate conforme percentual, o Estado deve promover políticas de estímulos como também formas de desenvolvimento de talentos mediante as participações de sociedades civis organizada, promovendo oficinas de capacitação, de desenvolvimento de empreendedorismos, cooperativas e alternativas que possam atender uma demanda cada vez maior de uma sociedade em constante evolução e interação que ultrapassa das fronteiras nacionais, inclusive previsto no parágrafo único do artigo 35 do Estatuto da Pessoa com Deficiência.

\section{A PERSPECTIVA DE INCENTIVOS PARA CONTRATAÇÃO DE PESSOAS COM DEFICIÊNCIA}

A perspectiva do Estado de criar incentivos para o cumprimento de obrigações não é uma ideia nova, tendo em vista o objetivo de alcançar um nível maior de atendimento a determinado preceito através de elementos motivadores.

Para Norberto Bobbio (2007, p. 23), as sanções negativas sempre tiveram maior relevo no campo jurídico somente com relação à proteção de interesses mediante a possibilidade de estabelecer repressões para os atos considerados desviantes, sendo que a conduta resultante disso sempre tem sido uma preocupação constante em penalizar um comportamento que não esteja de acordo com os preceitos determinados pela lei.

A ideia entronizada de sanção positiva é contrária àquela que normalmente é difundida pelo Direito como sendo a da sanção negativa. Se a aura da sanção negativa conduz a impressão de castigo por uma ação considerada má, a sanção positiva na esteira do raciocínio de Norberto Bobbio (2007) é mais uma reação a uma ação boa.

A reflexão possibilita também acrescer que o objetivo de uma sanção positiva caminha para a prevenção de ocorrências de ações consideradas prejudiciais tanto do ponto de vista individual como coletivo. 
As sanções positivas seguem uma concepção de que o atendimento de determinados preceitos pode ser recompensado, isto é, a manifestação de condutas apontadas como benéficas poderiam ser motivadas para a repetição por meio de incentivos.

As sanções positivas também podem ser chamadas de sanções premiais, que possuem o mesmo sentido de adesão espontânea no cumprimento de obrigações mediante incentivos e vantagens (REALE, 2003, p. 76).

Para Dimitri Dimoulis (2013, p. 109), existem diferenças entre a sanção positiva e a sanção negativa. A primeira estabelece uma consequência favorável a ser aplicada em caso de comportamento harmônico com a norma e na segunda, a diferença é inversa, pois ocorre consequência gravosa quando prática comportamento em desacordo com a norma.

A utilização de sanções positivas como forma de cumprimento de obrigações, possui proximidade peculiar com a ideia de reforço positivo de Skinner. ${ }^{3}$

A teoria do condicionamento operante de Skinner reporta que determinados comportamentos podem ser desenvolvidos mediante um esquema de reforçamento, ou seja, mediante a manifestação de um comportamento pretendido com a exposição de elemento agradável ao sujeito e haveria a possibilidade de repetição desse comportamento na medida em que fosse sempre apresentado o elemento agradável.

Para Wayne Weiten (2010, p. 177) o tema fornece exemplos simples do cotidiano das pessoas que ilustram a ideia de reforço:

O princípio do reforço pode parecer simples, mas é imensamente poderoso. Skinner e seus seguidores mostraram que muito do comportamento cotidiano das pessoas é regulado pelo reforço. Por exemplo: você estuda muito porque boas notas provavelmente advirão como resultado trabalha porque esse comportamento resulta em seu pagamento no fim do mês, e talvez trabalhe mais arduamente porque promo-

${ }^{3}$ Burrhus Frederic Skinner (1907-1990) foi autor e psicólogo americano. Conduziu trabalhos pioneiros em psicologia experimental e foi o propositor do behaviorismo radical, abordagem que busca entender o comportamento humano. 
ções e aumentos salariais poderão advir de tal comportamento. Você conta piadas e seus amigos riem então conta mais. O princípio do reforço governa claramente complexos aspectos do comportamento humano. Paradoxalmente, este princípio surgiu da pesquisa de Skinner sobre o comportamento de ratos e pombos em situações excepcionais simples.

Essa junção permite compreender que, se fossem introduzidos elementos reforçadores, haveria a possibilidade de que determinado comportamento fosse repetido sempre que fosse estimulado.

No campo jurídico, as sanções positivas de Bobbio se combinam com o reforço positivo de Skinner quando aplicado com a estratégia de premiar condutas que a sociedade entende ser de importância para a introdução de melhorias de condições de vida que favoreçam a comunidade.

A legislação brasileira no tocante à melhoria das condições de vida das pessoas com deficiência não passou despercebida com relação à promoção de incentivos para a contratação.

A Lei $n^{0}$ 8.212, de 24 de julho de 1991, que dispõe sobre a organização da Seguridade Social, instituiu o plano de custeio, no $\S 4^{\circ}$ do artigo 22:

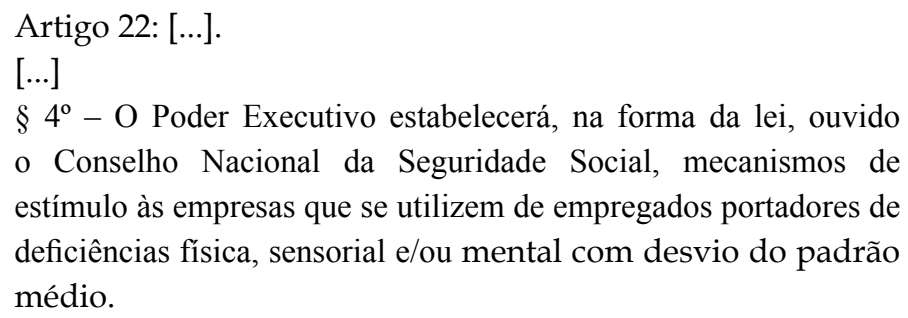
estímulo às empresas que se utilizem de empregados portadores de deficiências física, sensorial e/ou mental com desvio do padrão médio.

O fato que chama a atenção é que a referida lei tem a mesma data de promulgação da Lei $n^{\circ} 8.213$, ou seja, 24 de julho de 1991, que estabeleceu no artigo 93 a obrigação de reserva de percentual de vagas de trabalho para as pessoas com deficiência, conforme o quadro total de empregados na iniciativa privada.

No entanto, esses foram os espasmos criativos alternativos para incentivo a integração da pessoa com deficiência no mercado de trabalho, sendo 
ainda muito distante da busca criativa de outras soluções que fugissem do trivial obrigatório de contratar.

Se a ideia de reforçar positivamente as empresas que contratam pessoas com deficiência mediante abatimentos fiscais pode contrabalancear o orçamento empresarial e fomentar boas práticas que estimulem a integração e não simplesmente a incorporação do sujeito na esteira de algum setor da empresa.

Ainda mais, o sentido de incentivos poderia atender a possibilidade de que empresas que não encaixam pela natureza de suas operações de negócio, contribuir para um fundo específico de recursos para investimento em aprimoramento técnico e profissional para as pessoas com deficiência.

A busca de alternativas mediante os incentivos pode contribuir para a efetivação da obrigação de contratar não seja uma sanção punitiva pela via da multa, mas um prisma de valoração da dignidade da pessoa com deficiência.

Por outro lado, a efetivação do atendimento da obrigação de contratar na iniciativa privada atualmente se ocorre pela "caneta" da fiscalização dos auditores do MTE regulamentada pela Instrução Normativa $n^{\circ}$ 98, de 15 de agosto de 2012 e pelo Ministério Público e demais entidades mencionadas no artigo $3^{\circ}$ da Lei ${ }^{\circ}$ 7.853, de 24 de outubro de 1989, alterado pela Lei ${ }^{\circ} 13.146$, de 06 de julho de 2015.

Por outro lado, o diploma legal que estabelece a possibilidade de utilização de "mecanismos de estímulo às empresas" não foi efetivado, pois as legislações pouco asseguraram alguma forma de incentivo para a contratação e manutenção de emprego da pessoa com deficiência.

Muito pelo contrário, a legislação assegura a obrigação de contratar, mas não oferece em contrapartida estímulos que reforçam a contratação de pessoas com deficiência e nem incentivos de manutenção dos empregos.

A contratação e manutenção dos empregos para as pessoas com deficiência ficaram na conjunção das sanções negativas, que punem com multas os empregadores que deixam de contratar conforme o preceito do artigo 93 da Lei $n^{\circ} 8.213$, de 24 de julho de 1991, e no mesmo molde no $\S 1^{\circ}$ autoriza a demissão do empregado com deficiência somente após a contratação de outro com deficiência ou reabilitado.

Os estímulos para contratação de pessoas com deficiência no modelo 
brasileiro passaram ao largo da proposta de sanções positivas como formas de incentivos.

Atualmente, vigoram alguns incentivos como o previsto no artigo 24, inciso XX da Lei $\mathrm{n}^{\circ}$ 8.666, de 21 de junho de 1993, que trouxe a possibilidade de dispensa de licitação pelos órgãos ou entidades da Administração Pública: "na contratação de associação de portadores de deficiência física, sem fins lucrativos e de comprovada idoneidade, $[. . .]^{\prime \prime}$, além da expectativa do novo inciso $\mathrm{V}$ do artigo $3^{\circ}$ da referida lei citada que traduz o benefício pelo critério de desempate para a empresa que comprove o cumprimento de reserva de cargos para a pessoa com deficiência ou reabilitada da Previdência Social e que atenda às regras de acessibilidade, como também o $\S 5^{\circ}$ do citado artigo que foi modificado no sentido da possibilidade das empresas que atendam os percentuais de contratação de pessoas com deficiência terem preferência nos processos de licitação que envolve produtos manufaturados e serviços nacionais que atendam às normas técnicas brasileiras.

Essa situação demonstra que o perfil do modelo brasileiro adotado para tratar as questões de inserção da pessoa com deficiência no mercado de trabalho ainda pairam no sentido de trazer obrigações para os empregadores sem que haja, em contrapartida pelo Estado, incentivos para a contratação e a manutenção desses empregos.

Neste sentido, o Estado brasileiro mantém uma política de autuações por descumprimento da lei que traduz na carência de alternativas de incentivo de empregos para a melhoria das condições de acesso e a geração e empregos, principalmente para as pessoas com deficiência, a não ser pela única via da obrigação determinada pelo artigo 93 da Lei n ${ }^{\circ}$ 8.213, de 24 de julho de 1991, e pelas fiscalizações dos auditores do MTE e ações do Ministério Público.

\section{CONSIDERAÇÕES FINAIS}

A Constituição Federal de 1988 foi primorosa em estabelecer direitos e garantias para as pessoas com deficiência de tal modo que sua base possibilitou a proteção normativa em diversos temas como o trabalho, saúde, previdência, educação, mobilidade, etc. 
Tamanha geração de direitos possibilitou a criação uma blindagem normativa que regulamentassem os direitos permitindo a referência normativa a integração social da pessoa com deficiência.

A condição de obrigação no cumprimento da lei por um lado favorece que sejam implantadas condições de mudança que não seriam aceitas livremente. O exemplo dessa condição foi a obrigação de reservar vagas de trabalho na iniciativa privada conforme percentual do quadro de pessoal para as pessoas com deficiência.

É reconhecível que essa obrigação trouxe para o mundo do trabalho a pessoa com deficiência, principalmente pela atuação punitiva dos auditores do trabalho que possibilitou tornar fato a incorporação do trabalhador com deficiência no mundo do trabalho, visto que ainda que não é possível mensurar o trabalho como sendo digno ou apenas representa cumprimento de quota ou seja, não se pode determinar se é integrado ou incorporado.

Independentemente do impasse quanto a incorporação ou da integração, a sua participação no mundo do trabalho é de fato uma realidade que não era vista no passado, principalmente quando não havia a fiscalização dos auditores do trabalho.

Logo sob sanção negativa, representada pela ameaça da autuação pelos auditores do trabalho e Ministério Público, o trabalhador com deficiência passou a ser visto no contexto do "chão de fábrica".

A obrigatoriedade de reservar vagas de trabalho para as pessoas com deficiência acaba tendo sua notoriedade pelo fato da punição via multas para as empresas que não atendem a quota ou que não conseguem atender por razões de negócio, ou seja, a legislação acaba por trazer um forte apelo de punição, de sanção negativa materializada pela multa.

Por outro lado, a visão de um Direito impregnado somente pela força ordinária punitiva não atende todo o anseio da coletividade que enfrenta turbulências que necessitam de respostas condizentes diante de um cenário multicultural e de visões globalizadas.

É notório que a estratégia pública carrega em muitas situações, a vontade de buscar melhorar as condições para grupos minoritários e, para tanto, ao formular as estratégias concebem dentro de uma esfera teórica dissociada 
da prática da vida, trazendo consequências que não estavam previstas no plano original.

Em algumas situações é necessária evoluir e aprimorar a legislação buscando adequar à realidade social, tendo em vista que seu alcance tenha sido reduzido pela sua descontinuidade de sua eficácia.

A ideia sugestiva aponta pela possibilidade de atrelar outras formas de melhoria de atendimento normativo de forma a fomentar condutas e regulações que permitam construir relacionamentos sociais positivos que incentivem a redução de conflitos no seio da sociedade.

A proposta de atrelar incentivos ou estímulos positivos em forma de abatimentos fiscais e sociais ou quando aquelas empresas que não conseguem contratar pessoas com deficiência pela natureza do seu negócio, podendo em contrapartida efetuar pagamento de quotas para um fundo de aprendizagem técnica para pessoas com deficiência representa alternativas que tratam de reforços positivos para que comportamentos se repitam mediante premiações que permitam estimular o cumprimento de aumento de contratações de pessoas com deficiência.

Desta forma, incentivar com medidas que estimulem comportamentos desejados, como forma de premiações, podem preencher as lacunas que a obrigatoriedade do cumprimento da reserva de vagas não alcançou, pois o objetivo maior é integrar a pessoa com deficiência na sociedade e o trabalho é uma das formas sociais de melhor eficiência, pois representa a oportunidade da pessoa com deficiência desenvolver a sua autonomia e o poder de decisão de sua vida, alcançando a sua dignidade.

\section{REFERÊNCIAS}

ARAUJO, Luiz Alberto David; NUNES JÚNIOR, Vidal Serrano. Curso de Direito Constitucional. 17. ed. São Paulo: Verbatim, 2013.

BARROSO, Luis Roberto. O Controle de Constitucionalidade no Direito Brasilei- 
ro: exposição sistemática da doutrina e análise crítica da jurisprudência. 6. ed. rev. e atual. 2. tirag. São Paulo: Saraiva, 2014.

BOBBIO, Norberto. Da Estrutura à Função: novos estudos de teoria do direito. Tradução de Daniela Beccaccia Versiani. Barueri: Manole, 2007.

BRASIL. Constituição da República Federativa do Brasil. Constituição (1988). Disponível em: <http://www.planalto.gov.br/ccivil_03/constituicao/constituicao. htm>. Acesso em: 07 abr. 2018.

. Lei $n^{\circ} 8.666$, de 21 de junho de 1993. Disponível em:<http:/ / www.planalto. gov.br/ccivil_03/Leis/18666cons.htm>. Acesso em: 07 abr. 2018.

Decreto $\mathrm{n}^{0}$ 3.298, de 20 de dezembro de 1999. Disponível em: <http:// www.planalto.gov.br/ccivil_03/decreto/d3298.htm>. Acesso em: 05 abr. 2018.

Instrução Normativa $n^{0}$ 98, de 15 de agosto de 2012. Portal do Trabalho e Emprego. Disponível em: <http:// portal.mte.gov.br/legislacao/instrucao-normativa-n-98-de-15-de-agosto-de-2012.htm>. Acesso em: 07 abr. 2018.

Lei $\mathrm{n}^{0}$ 13.146, de 06 de julho de 2015. Disponível em: <http:/ /www.planalto.gov.br/ccivil_03/_Ato2015-2018/2015/Lei/L13146.htm>. Acesso em: 08 abr. 2018.

. Lei $\mathbf{n}^{\circ} 8.212$, de 24 de julho de 1991. Disponível em: <http:/ / www.planalto.gov.br/ccivil_03/leis/18212cons.htm>. Acesso em: 07 abr. 2018.

Lei ${ }^{0}$ 8.213, de 24 de julho de 1991. Disponível em: <http:/ / www.planalto.gov.br/ccivil_03/leis/18213cons.htm>. Acesso em: 07 abr. 2018.

CARVALHO, José Raimundo de. Acessibilidade e Locomoção da Pessoa com Deficiência e seus Direitos Constitucionais. 2012. 213 f. Dissertação (Mestrado em Direito Constitucional). Centro de Pós-Graduação, Instituto Toledo de Ensino, Bauru, SP, 2012. 
DIMOULIS, Dimitri. Manual de Introdução ao Estudo do Direito. 5. ed. rev. atual. e ampl. São Paulo: Revista dos Tribunais, 2013.

GAVÁN, Alexander Castrillo; MARES, Alberto Ibarra. Empreendimiento para Creación con Responsabilidade Social Empresarial (RSE): metodologia y aplicación del modelo GEM. Biblioteca Virtual Eumed.Net. Bogotá: Fundación Universitaria Andaluza Incisoa Garcilaso. 2013. Disponível em: <http:/ / www.eumed.net/librosgratis/2014/1363/index.htm>. Acesso em: 05 mar. 2018

GRAU, Eros Roberto. O Direito Posto e o Direito Pressuposto. 5. ed. São Paulo: Malheiros, 2003.

MARTINS, Ives Gandra. Discriminação às Avessas. In: Revista Exame. Publicação de 02 jan. 1996. Disponível em: <http://exame.abril.com.br/revista-exame/edicoes/600/noticias/discriminacao-as-avessas-m0047506>. Acesso em: 05 mar. 2018.

MOREIRA, Glauco Roberto Marques. Pessoas Portadoras de Deficiência: pena e Constituição. Porto Alegre: Sergio Antonio Fabris Editor, 2008.

ORGANIZAÇÃO INTERNACIONAL DO TRABALHO. Declaração da OIT Sobre os Princisoípios e Direitos Fundamentais no Trabalho. 2012. Disponível em: <http://www.oitbrasil.org.br/sites/default/files/topic/oit/doc/declaracao_ oit_547.pdf>. Acesso em: 07 mar. 2018.

PASTORE, José. Oportunidade de Trabalho para Portadores de Deficiência. São Paulo: LTr, 2000.

REALE, Miguel. Lições Preliminares de Direito. 27. ed. São Paulo: Saraiva, 2003.

SANDEL, Michael J. Justiça: o que é fazer a coisa certa. Tradução de Heloisa Matais e Maria Alice Máximo. 9. ed. atual. Rio de Janeiro: Civilização Brasileira, 2012.

SASSAKI, Romeu Kazumi. Inclusão: construindo uma sociedade para todos. 8. ed. Rio de Janeiro: WVA, 2010. 
SILVA, José Afonso da. Aplicabilidade das Normas Constitucionais. 3. ed. São Paulo: Malheiros, 1998.

WEITEN, Wayne. Introdução à Psicologia: temas e variações. Tradução de Clara A. Colotto, José Carlos B. dos Santos, Maria Lúcia Brasil e Zaira G. Botelho. 7. ed. São Paulo: Cengage Learning, 2010. 